\author{
JANICE MYCK-WAYNE \\ California State University \\ Fullerton
}

\author{
ANNA JAKONIUK-DIALLO \\ Uniwersytet im. Adama Mickiewicza \\ $w$ Poznaniu
}

\title{
SUPPORTING VERY YOUNG CHILDREN WITH HEARING LOSS IN THE UNITED STATES
}

\begin{abstract}
Myck-Wayne Janice, Jakoniuk-Diallo Anna, Supporting Very Young Children with Hearing Loss in the United States [Wspieranie bardzo małych dzieci z ubytkiem słuchu w Stanach Zjednoczonych Ameryki]. Studia Edukacyjne nr 41, 2016, Poznań 2016, pp. 203-216. Adam Mickiewicz University Press. ISSN 1233-6688. DOI: 10.14746/ se.2016.41.12

The main objective of supporting the development of children with hearing loss is to optimize the process of acquiring and developing their linguistic competence and communication, despite the existing restrictions in this regard. This task is particularly important in relation to children with hearing parents, because their case involves the removal of barriers to communication between a child with a hearing impairment and his dearest and nearest. Opposite this objective comes out a number of methods, so-called auditory-verbal communication. The purpose of this article is to analyze the use of bilingualism of early support development of deaf children as the most popular model used in the United States. In this country, in which deaf people have won the right to be treated as a cultural minority rather than the disabled, a child with hearing loss has a suitable status predisposed to bilingualism, which entails the need to include it in the interactions supporting the development, discussed in the article.
\end{abstract}

Key words: children, deaf, hearing, support, bilingualism

The main objective of supporting the development of children with hearing loss is to optimize the process of acquiring and developing their linguistic competence and communication, despite the existing restrictions in this regard. This task is particularly important in relation to children with hear- 
ing parents, because in their case involves the removal of barriers to communication between a child with a hearing impairment and his closest people. Opposite this objective comes out a number of methods, so-called. auditory-verbal communication. They assume the need to detect early hearing loss as quickly as possible supply the child in the auditory prosthesis, ie. Devices or implants and auditory rehabilitation early start - language. A special role in the implementation of auditory training is attributed to the parents. Their acceptance of the child's empathic understanding facilitate the process of mutual interaction and communication. Fit guardian for the child and entered in the process sensitivity to signals that are sent to what the lack of skills in the child speech sound, encourages them to try to communicate with the environment. Fit, always requires taking into account children's abilities and limitations, therefore plays a key role, not only in the rehabilitation of auditory-verbal child, but also in developing his skills to communicate using gestures. The use of bilingual model of early support development of deaf children is the most popular in the United States. In this country, in which deaf people have won the right to treat them as a cultural minority, not disabled, a child with hearing loss is suitable status predisposed to bilingualism, which entails the need to include it as described below interactions supporting the development.

Intervention and habilitation for very young children with hearing loss requires a comprehensive system of audiologic and language supports to the child and family. Two primary factors influence the intervention and education of very young deaf and hard of hearing children in the United States. The first is the Universal Newborn Hearing Screening program (UNHS) and the second is the provision of the Individuals with Disability Education Act (IDEA, 2004, The Individuals with Disabilities Education Act, 20 USC §14311445, Infants and Toddlers with Disabilities, Part C). Both of these programs construct the framework for early intervention services for infants and toddlers with hearing loss and their families. Newborn hearing screening is predicated on the evidence that early detection of hearing loss results in better outcomes for language acquisition for children with hearing loss. ${ }^{1}$ Research has documented that if infants with hearing loss begin intervention by 6 months old and there is active and consistent parental involvement, they can develop comparable language skills their hearing counterparts. ${ }^{2}$

${ }^{1}$ C. Yoshinaga-Itano, Achieving optimal outcomes from EHDI, The ASHA Leader, 2011 September, 20, 16(11), p. 14-17. Retrieved from www.asha.org.

2 M.P. Moeller, Early Intervention and language development in children who are deaf and hard of hearing, Pediatrics, 2000, 106, E43; C. Yoshinaga-Itano, Levels of evidence: universal newborn hear- 
Services and interventions, once hearing loss has been diagnosed, are required under Part C of IDEA. Over the past 13 years, UNHS has increased the number of very young children identified with hearing loss. As part of the newborn hearing screen process, legislative actions authorized the development of the Early Hearing Detection and Intervention (EHDI) Program. ${ }^{3}$ Congress first authorized the EHDI programs in 2000. The legislation and subsequent funding by Congress assisted in the establishment of statewide EHDI programs across the United States that are identifying children with hearing loss and directing them to early intervention services.

The foremost goal of the family centered, community based EHDI system is to maximize the linguistic and communicative competence and literacy development of children who are deaf or hard of hearing. Mechanisms to accomplish this goal are imbedded in Principles 2, 3, and 5 endorsed by the Year 2000 Position Statement of the Joint Committee of Infant Hearing. ${ }^{4}$ Several principals of EDHI and their implication for service will be outlined in this paper.

\section{Early Identification}

EDHI Principle 2. "All infants who do not pass the birth admission screen and any subsequent rescreening begin appropriate audiologic and medical evaluations to confirm the presence of hearing loss before three months of age."

According to AAP (2007), hearing loss is one of the most frequently occurring birth defects; approximately 3 infants per 1,000 are born with moderate, profound or severe hearing loss. Hearing loss is even more common in infants admitted to intensive care units at birth. If hearing loss is not detected and treated early, it can impede speech, language and cognitive de-

\footnotetext{
ing screening (UNHS) and early hearing detection and intervention systems (EHDI), Journal of Communication Disorders, 2004, 37(5), p. 451-465, http://dx.doi.org/10.1016/j.jcomdis.2004. 04.008; C. Yoshingaga-Itano et al., Language of early-and later-identified children with hearing loss, Pediatrics, 1998, 102, p. 1161-1171.

${ }^{3}$ B. Vohr, Infants and children with hearing loss-Part 2: Overview, Mental Retardation and Developmental Disabilities Research Reviews, 2003, 9, p. 218-219.

4 American Academy of Pediatrics Task Force on Newborn and Infant Hearing, Newborn and infant hearing joss: Detection and intervention, Pediatrics, 1999, 133, p. 527-529; Joint Committee on Infant Hearing. Joint Committee on Infant Hearing Year 2000 Position Statement: Principles and Guidelines for Early Hearing Detection and Intervention Programs. Available at: http://www.infanthearing.org/jcih/.
} 
velopment. Over time, such a delay can lead to significant educational costs and learning difficulties.

Prior to the (UNHS), children were rarely identified with a hearing loss before 2 years of age and many were identified even later. ${ }^{5}$ Early intervention is effective in preventing or minimizing the negative impact of hearing loss on speech and language development. ${ }^{6}$ In the last 20 years legislation and technology have positively impacted the lives of people with hearing loss, truly "opening the world of communication" to thousands and thousands of children and adults. EHDI programs include screening (the initial test of infants for hearing loss), audiological diagnostic evaluations (to confirm hearing loss), and early intervention (including medical services, early intervention programs, and family support) to enhance language, communication, cognitive and social skill development, needed to be successful in school and all other aspects of life. Every state in the U.S.A has an (EHDI) program.

The National Center for Hearing Assessment and Management ${ }^{7}$ reports that early detection and early habilitation of hearing loss can save $\$ 400,000$ in special education costs for one child by the time the child graduates from high school. Most of the 50 states in the United States have taken action to ensure children are screened and treated early for hearing loss. Screening programs are typically cost-effective and amount to about $\$ 10-\$ 50$ per baby, according to NCHAM. Nationally, screening rates have increased significantly over time. Currently, more than 97 percent of all newborns born in the United States are screened for hearing loss shortly after birth. ${ }^{8}$ Many infants with hearing loss are identified at a few weeks of age, when appropriate treatment programs can optimize their long-term speech and language, cognitive, and social skills. Recent data from the Centers for Disease Control and Prevention (CDC) demonstrate that 77 percent of children confirmed to have a permanent hearing loss were enrolled in intervention programs by six months of age. States have taken a variety of approaches to this

${ }^{5}$ L. Holte et al., Factors influencing follow-up to newborn hearing screening for infants who are hard of hearing, American Journal of Audiology, 2012, 21(2), p. 163-174.

${ }^{6}$ R. Calderon, S. Naidu, Further support of the benefits of early identification and intervention with children with hearing loss, Volta Review, 1999, 100, p. 53-84; C.R. Kennedy et al., Language ability after early detection of permanent childhood hearing impairment, The New England Journal of Medicine, 2006, 354, p. 2131-2141; M.P. Moeller, Early Intervention and language development.

7 National Center for Hearing Assessment and Management (NCHAM), 2010, State EHDI/UNHS mandates: Summary table. Retrieved May 17, 2013, from http://www.infanthearing. org/legislative/summary/index.html.

${ }^{8} \mathrm{~K}$. Houston et al., Is the infrastructure of EHDI programs working? Volta Review, 2011, 111(2), p. 225-242. 
issue: some mandate that all hospitals or birthing centers screen infants for hearing loss before they are discharged; some mandate that insurance policies cover the cost of the screening; others use state dollars to fund screening programs. Still other states require that information on hearing screening be available to parents before they leave the hospital. Fourteen states allow newborns to be exempt from universal hearing screening programs if a parent objects to the testing. The national guidelines for UNHS recommend that (a) newborns be screened for hearing loss before 1 month of age, (b) diagnose hearing loss before 3 months of age, and (c) enroll those identified with hearing loss in early intervention before 6 months of age. According to the Centers for Disease Control and Prevention (CDC), in 2006, 91.2\% of newborns were screened for hearing loss, and $2.1 \%$ did not pass that screening. Of those who did not pass the screening, $29.9 \%$ were found to have normal hearing. By 2009, the latest year for which data are available 9 , national statistics improved: and $5.8 \%$ were found to have hearing loss, but no diagnosis could be documented in $64.2 \%$ of the babies who did not pass the NHS (Gaffney, Green, Gaffney, 2010).

While identification and diagnosis of hearing loss has greatly improved, unfortunately challenges remain for many families in accomplishing recommended follow-up steps. Identified barriers to follow-up failed screenings include (a) limited access to audiologists with pediatric expertise, (b) appointment wait times, (c) the presence of medical comorbidities, and (d) the presence of unilateral or mild hearing loss. ${ }^{10}$ In addition, families of hard of hearing infants may have difficulty understanding the need to follow up on a failed screening, given that they may observe the baby responding to loud sounds in the environment. While the UNHS serves to identify infants with hearing loss, infants and children can acquire hearing loss after they successfully pass the initial screening. Audiological monitoring should be provided every 6 months until age 3 .

\section{Intervention and Services}

EDHI Principle \#3. "All infants with confirmed permanent hearing loss receive services before six months of age in interdisciplinary intervention

${ }^{9}$ U.S. Centers for Disease Control, 2010.

${ }^{10}$ R.C. Folsom et al., Identification of neonatal hearing impairment: Recruitment and follow-up, Ear and Hearing, 2000, 21, p. 462-470; M.P. Moeller et al., Strategies for educating physicians about newborn hearing screening, Journal of the Academy of Rehabilitative Audiology, 2006, 39, p. 1132; M.P. Moeller, K.R. White, L. Shisler, Primary care physicians' knowledge, attitudes, and practices related to newborn hearing screening, Pediatrics, 2006, 118, p. 1357-1370. 
programs that recognize and build on strengths, informed choice, traditions, and cultural beliefs of the family."

Intervention for hearing loss begins once the hearing loss has been diagnosed. Families are referred to local education and support services to receive intervention. Part C of IDEA (2004) authorizes states to provide the early intervention services. Federal law in the United States requires services to very young children (birth to up to 3 years of age) and their families who are at risk for or who have a developmental delay (IDEA, 2004). The law was enacted as a consequence of parent advocacy, legislation brought forth by politicians with family and/or friends with disabilities and research, services to very young children with disabilities. The legislation also intends to enhance each state's capacity to expand and improve existing early intervention services provided to infants and toddlers with disabilities. Services are free and are outlined in a document, the individualized family service plan (IFSP), developed with the family and the provider of service. ${ }^{11}$

The family-centered service delivery model inherent in early intervention practice recognizes and values the family's vital role as caregiver and decision-maker when identifying family strengths, resources and priorities and when determining services for their child.12 In addition, intervention and services must be included in the child and family's natural environment. Natural environments are defined as the places in which you would find a typical infant and toddler. This includes, but not limited to, services in the child's home, daycare, and caregiver's home. The shift is from center-based and clinically provided services. Given the centrality of the family's role in early detection of hearing loss and intervention, there is growing recognition of the importance of family well-being, family resources and supports, and the involvement of families in services for children who are deaf or hard of hearing. Educators of the deaf and service providers in related services (audiologists and speech therapists) strive to foster families' strengths and support the child's development within the context of the family. The term family support refers to varied resources to address the family's needs related to emotional well-being, health, material well-being, parenting, disabilityrelated considerations, and family interactions. ${ }^{13}$

11 V. Howard, B. Williams, C. Lepper, Very young children with special needs: A foundation for educators, families and service providers (4th Ed.), New York 2010.

${ }_{12}$ M. Espe-Sherwindt, Family-centered practice: Collaboration, competency and evidence, Support for Learning, 2008, 23(3), p. 136-143.

${ }^{13} \mathrm{~J}$. Myck-Wayne, Early intervention services for very young children: Elements of Part $C$, The Russian-American Education Forum: An Online Journal, 2011, 3(1). 


\section{Communication Choice}

Principle \#5. "Infant and family rights are guaranteed through informed choice, decision-making, and consent."

A communication option, mode, modality, or method is the means by which the child and family receive and express language. The choice of a communication modality that facilitates language development and allows the child who is hard of hearing or deaf to readily engage in communication interchanges with family and caregivers is a primary issue throughout childhood. ${ }^{14}$ Parent(s) who have children identified with hearing loss will receive a printed, standardized resource manual that includes clear, objective, explanatory information on each communication option. They receive information about communication options in a standardized format in order to make informed choices and decisions regarding their child's intervention and education. The six primary communication options include a. AuditoryVerbal (Unisensory), b. Oral or Auditory/Oral, c. Bilingual/Bicultural (ASL/ESL), d. Cued Speech, and e. Total Communication. Table 1 outlines the communication options available for hard of hearing and deaf children and are each explained below.

Auditory-Verbal. The Auditory-Verbal (acoupedic;unisensory; auditory; auditory-only) approach has as primary goals (1) the development of spoken language acquired exclusively through the use of aided residual hearing and (2) the complete integration of the child who is hard of hearing or deaf into the community of individuals who use spoken language (Auditory-Verbal International; www.auditory-verbal.org). Consistent (every waking hour) use of amplification or cochlear implant technology is considered requisite for achieving the goals set forth in the approach. ${ }^{15}$ Audition is stressed so significantly that during language learning activities, the child is not permitted to view the lips or facial expressions of the speaker.

Auditory-Oral. Similar to the AV approach just described, the goal of the auditory-oral (oral; aural-oral) communication option is the development of spoken language and inclusion in the mainstream in school and in society at large. ${ }^{16}$ Early identification of hearing loss and early fitting and consistent use of hearing aids are also basic principles of this approach. Unlike the AV

\footnotetext{
14 A. Carney, M.P. Moeller, Treatment efficacy: hearing loss in children, Journal of Speech, Language, and Hearing Research, 1998, 41, p. S61-84.

${ }^{15}$ D. Goldberg, Educating children who are deaf and hard of hearing: Auditory-Verbal, ERIC Clearinghouse on Disabilities and Gifted Education, 1997 (www.eric.ed.gov).

${ }^{16}$ Alexander Graham Bell Association: www.agbell.org
} 
approach, children who develop spoken language using the auditory-oral approach use their aided residual hearing, as well as speechreading, facial expressions, and naturally occurring gestures. Consistent use of hearing aids/FM technology and provision of auditory training and speech therapy as well as specific practice in lipreading are critical features of the approach.

Cued Speech. Cued Speech ${ }^{17}$ comprises eight different handshapes and four different hand locations around the speaker's face as seen in Figure 2. Each of the eight handshapes represents a group (3- 4) of consonants. Consonants within a handshape group are distinguished through lipreading. Vowels are cued by moving the hand to one of four locations around the lower face and neck (at the lips, side of the lips, chin, and throat) with lip shape distinguishing the vowels (2-3) within a vowel group. The receiver of the cued speech observes the speaker's hand pattern, hand location, and lip position in order to distinguish among individual speech sounds; none are visually ambiguous.

Manually Coded English (MCE). Manually Coded English (MCE) is a visual representation of the spoken English language. ${ }^{18}$ Signs and fingerspelling are used to represent spoken English. Syntax follows the rules of spoken English; lexical items without specific signs are fingerspelled. Grammatical morphemes are conveyed by gestures or fingerspelling. Amplification is not necessary for an individual who uses a form of MCE. MCE is often used as the visual (signed) component of Total Communication and Simultaneous Communication approaches.

Total Communication (TC). Total Communication (TC) is a philosophy that promotes the simultaneous use of multiple modalities (e.g., signs, gestures, speechreading, and hearing) for the understanding of communication. ${ }^{19} \mathrm{TC}$ is the most widely used communication method in educational settings for the deaf. ${ }^{20}$ In the ideal TC environment, families (and EI personnel) would use signed English (MCE) accompanied by clear and visible speech at a normally loud conversational voice level. The infant or young children would use aided residual hearing and the visual cues available from signs and lipreading for receptive communication. The child is encour-

17 O.R. Cornett, Cued Speech, American Annals of the Deaf, 1967, 112, p. 3-13; www. cuedspeech.org

${ }^{18}$ G. Gustafson, Educating children who are deaf and hard of hearing: English based Sign Systems, ERIC Clearinghouse on Disabilities and Gifted Education, 1997 (www.eric.ed.gov).

${ }^{19}$ L. Hawkins, J. Brawner, Educating children who are deaf and hard of hearing: total communication, ERIC Clearinghouse on Disabilities and Gifted Education, 1997 (www.eric.ed.gov).

20 J.S. Gravel, J. O'Gara, Communication options for children with hearing loss, Mental Retardation and Developmental Disabilities Research Reviews, 2003, 9, p. 243-251. 
aged to use both signs and speech to communicate expressively. Families adopting a TC philosophy would need to learn MCE.

American Sign Language (ASL). American Sign Language (ASL) is a naturally evolved visual language used by the Deaf community in the U.S. Many members of the Deaf community, however, consider themselves to be bilingual: use both ASL and some form of spoken language (MCE) when communicating with the Deaf and hearing communities, respectively. ${ }^{21}$ The bilingual-bicultural (Bi-Bi) philosophy 22 advocates that children who are deaf be able to communicate in two languages (visual and a form of spoken) allowing them to experience two cultures (Deaf and hearing communities). The Bi-Bi philosophy holds that children who are deaf are inherently members of the Deaf community. The Bi-Bi approach supports early language learning through ASL with a form of spoken English taught as a second language later in elementary school. ${ }^{23}$

The evidence suggest that not one communication option is Available evidence suggests that no one single communication option is the best for infants and young children with hearing loss. Many factors will impact the family's decision. This is particularly true in the early months following confirmation of hearing loss, as the family comes to understand the hearing loss. What is most important is the early identification of hearing loss followed by a language-based early intervention that includes a team approach between the family and service providers. Early intervention in language development results in expressive and receptive communication abilities that are superior to those of children later identified. ${ }^{24}$ Family participation potentially increases the impact on language development. Therefore, an ongoing process that empowers parents, considers family dynamics, and continually evaluates the changing needs of the child appears to be the best means of ensuring the development of optimal communication in children with hearing loss. It is of extreme importance that parents be provided with current, accurate information, from non-biased sources, so they can make wellinformed decisions about their child's communication, and, if necessary, refine those decisions over time. ${ }^{25}$

${ }^{21} \mathrm{~S}$. Baker, K. Baker, Educating children who are deaf and hard of hearing: bilingual-bicultural education, ERIC Clearinghouse on Disabilities and Gifted Education, 1997 (www.eric.ed.gov).

${ }^{22}$ National Association of the Deaf: www.nad.org

23 S. Baker, K. Baker, Educating children who are deaf.

24 J.S. Gravel, J. O'Gara, Communication options for children.

${ }^{25}$ K.B. Decker, C.D. Vallotton, H.A. Johnson, Parents' communication decision for children with hearing loss: Sources of information and influence, American Annals of the Deaf, 2012, 157(4), p. 326-339. 


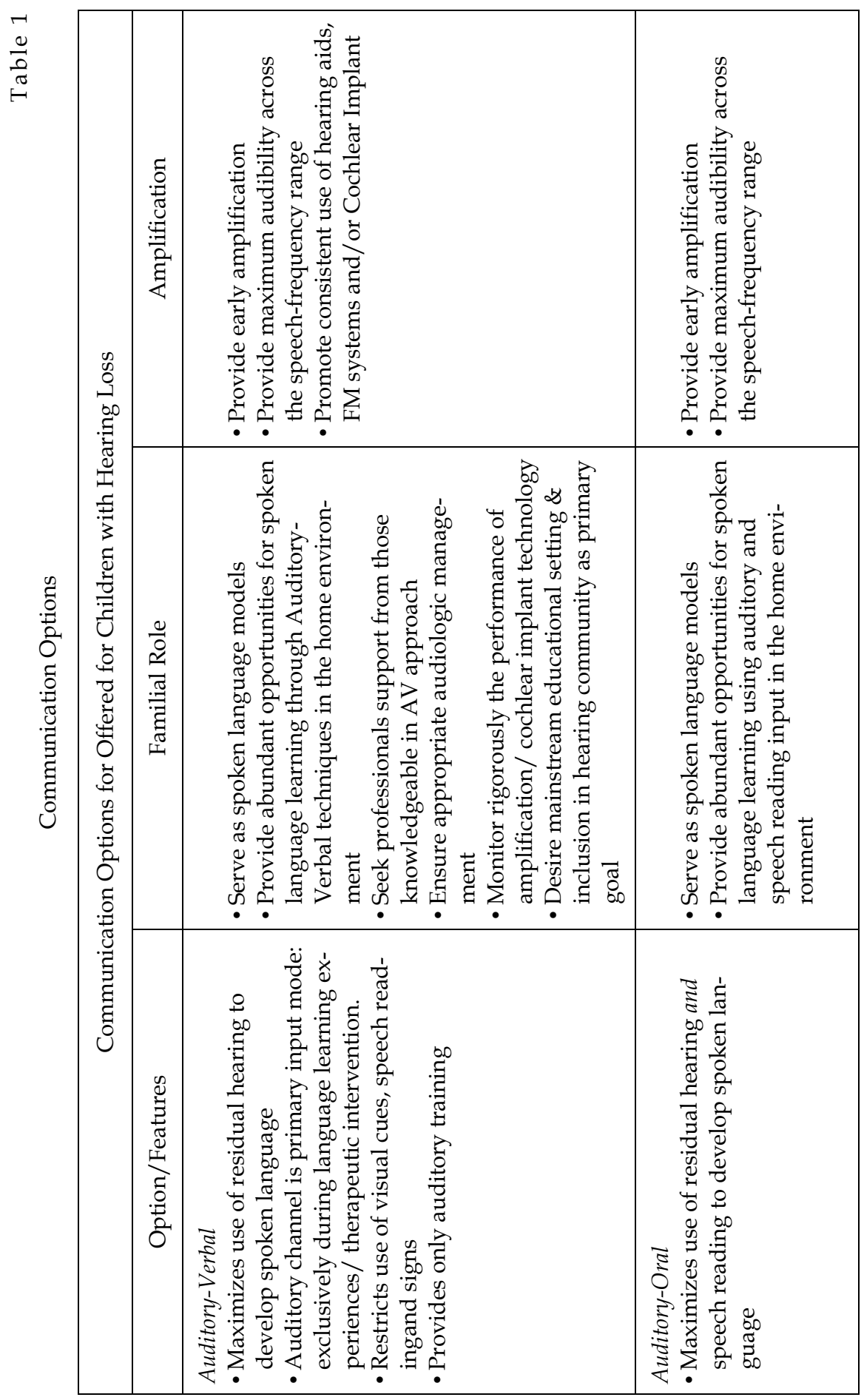




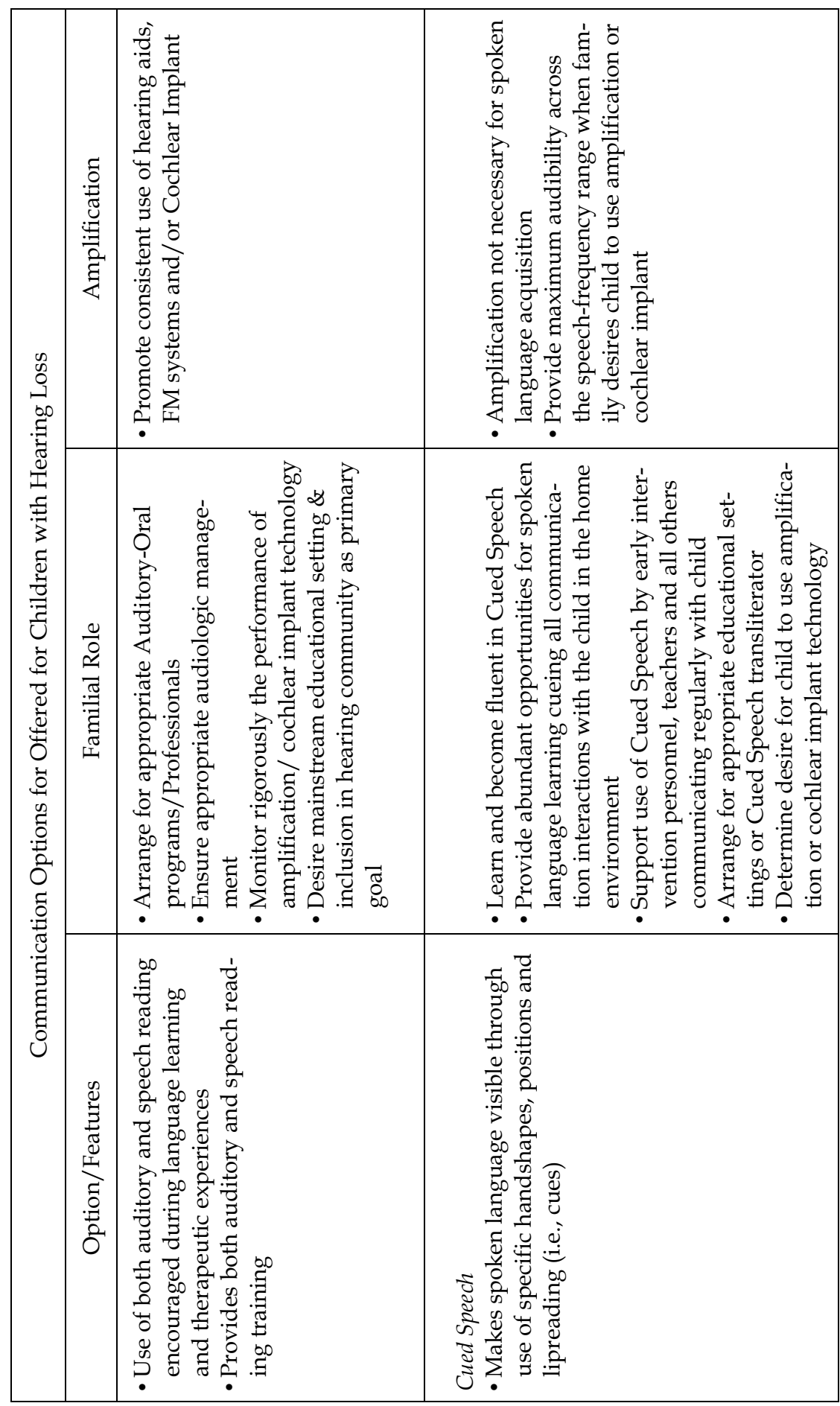




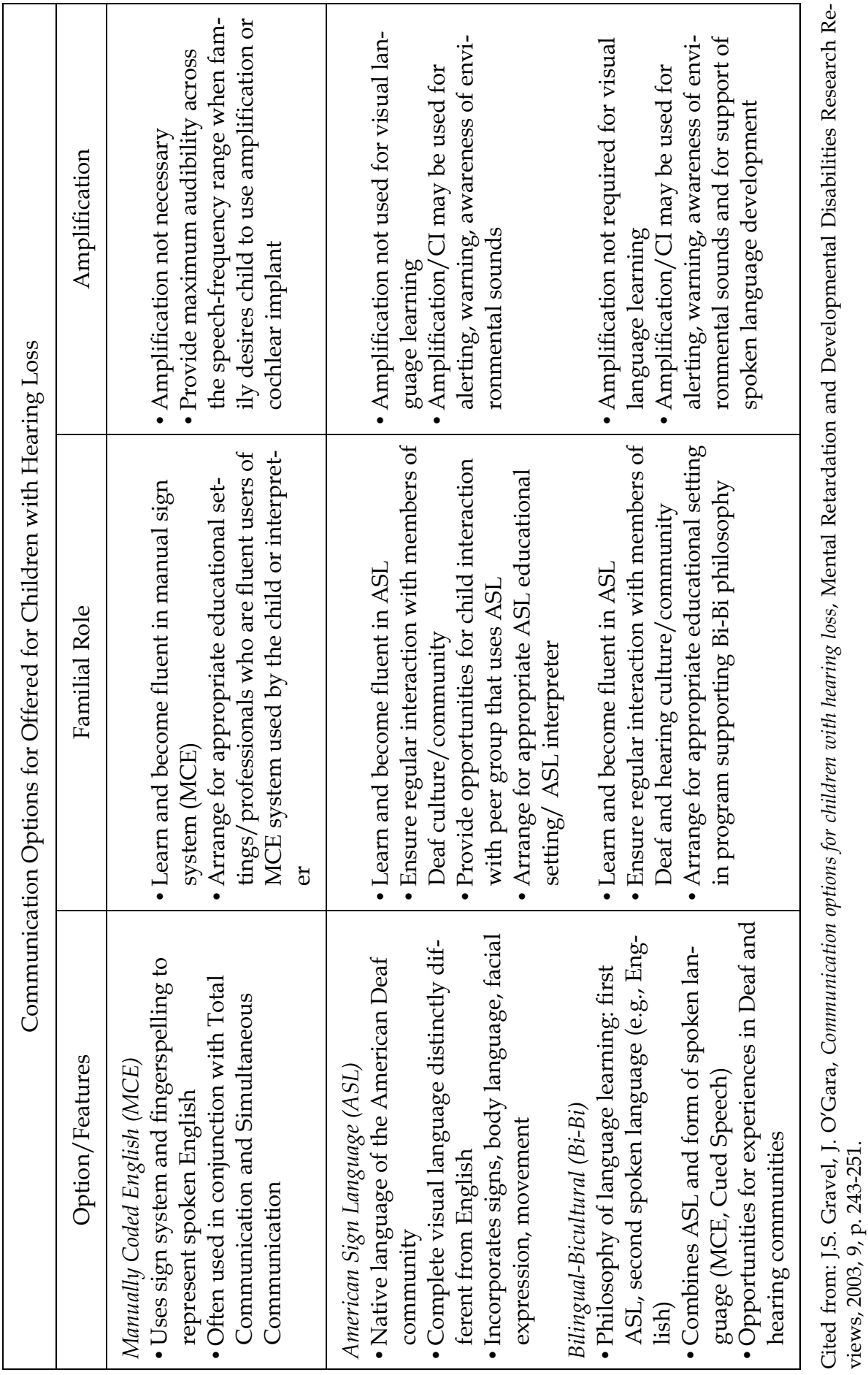




\section{BIBLIOGRAPHY}

Alexander Graham Bell Association: www.agbell.org

American Academy of Pediatrics Task Force on Newborn and Infant Hearing, Newborn and infant hearing joss: Detection and intervention, Pediatrics, 1999, 133.

American Academy of Pediatrics, Joint Committee on Infant Hearing, Year 2007 position statement: principles and guidelines for early hearing detection and intervention programs, Pediatrics, 2007, 120(4).

Baker S., Baker K., Educating children who are deaf and hard of hearing: bilingual-bicultural education, ERIC Clearinghouse on Disabilities and Gifted Education, 1997 (www.eric. ed.gov)

Calderon R., Naidu S., Further support of the benefits of early identification and intervention with children with hearing loss, Volta Review, 1999, 100.

Carney A., Moeller M.P., Treatment efficacy: hearing loss in children, Journal of Speech, Language, and Hearing Research, 1998, 41.

Centers for Disease Control and Prevention (CDC) 2010, Annual data: Early hearing detection and intervention (EHDI) program. Retrieved May 17, 2011 from http://www. cdc.gov/ncbddd/hearingloss/ehdi-data.html

Cornett O.R., Cued Speech, American Annals of the Deaf, 1967, 112.

Decker K.B., Vallotton C.D., Johnson H.A., Parents' communication decision for children with hearing loss: Sources of information and influence, American Annals of the Deaf, 2012, 157(4), Gallaudet University Press. Retrieved May 20, 2013, from Project MUSE database.

Espe-Sherwindt M., Family-centered practice: Collaboration, competency and evidence, Support for Learning, 2008, 23(3).

Folsom R.C., Widen J.E., Vohr B.R., Cone-Wesson B., Gorga M.P., Sininger Y.S., Norton S.J., Identification of neonatal hearing impairment: Recruitment and follow-up, Ear and Hearing, 2000, 21.

Goldberg D., Educating children who are deaf and hard of hearing: Auditory-Verbal, ERIC Clearinghouse on Disabilities and Gifted Education, 1997 (www.eric.ed.gov)

Gravel J.S., O'Gara J., Communication options for children with hearing loss, Mental Retardation and Developmental Disabilities Research Reviews, 2003, 9.

Gustafson G., Educating children who are deaf and hard of hearing: English based Sign Systems, ERIC Clearinghouse on Disabilities and Gifted Education, 1997 (www.eric.ed.gov)

Hawkins L., Brawner J., Educating children who are deaf and hard of hearing: total communication, ERIC Clearinghouse on Disabilities and Gifted Education, 1997 (www.eric. ed.gov)

Holte L., Walker E., Oleson J., Spratford M., Moeller M., Roush P., ... Tomblin J., Factors influencing follow-up to newborn hearing screening for infants who are hard of hearing, American Journal of Audiology, 2012, 21(2).

Houston K., Hoffman J., Muñoz K.F., Bradham T.S., Is the infrastructure of EHDI programs working? Volta Review, 2011, 111(2).

Howard V., Williams B., Lepper C., Very young children with special needs: A foundation for educators, families and service providers (4th Ed.), Upper Saddle River, Pearson Education, New York 2010. 
Joint Committee on Infant Hearing. Joint Committee on Infant Hearing Year 2000 Position Statement: Principles and Guidelines for Early Hearing Detection and Intervention Programs. Available at: http:/ /www.infanthearing.org/jcih/

Kennedy C.R., McCann D.C., Campbell M.J., Law C.M., Mullee M., Petrou S., Stevenson J., Language ability after early detection of permanent childhood hearing impairment, The New England Journal of Medicine, 2006, 354.

Moeller M.P., Early Intervention and language development in children who are deaf and hard of hearing, Pediatrics, 2000, 106, E43.

Moeller M.P., Eiten L., White K., Shisler L., Strategies for educating physicians about newborn hearing screening, Journal of the Academy of Rehabilitative Audiology, 2006, 39.

Moeller M.P., White K.R., Shisler L., Primary care physicians' knowledge, attitudes, and practices related to newborn hearing screening, Pediatrics, 2006, 118.

Myck-Wayne J., Early intervention services for very young children: Elements of Part $C$, The Russian-American Education Forum: An Online Journal, 2011, 3(1).

National Association of the Deaf: www.nad.org

National Center for Hearing Assessment and Management (NCHAM), 2010, State EHDI/UNHS mandates: Summary table. Retrieved May 17, 2013, from http://www. infanthearing.org/legislative/summary/index.html.

U.S. Centers for Disease Control, 2010.

Vohr B., Infants and children with hearing loss-Part 2: Overview, Mental Retardation and Developmental Disabilities Research Reviews, 2003, 9.

Yoshinaga-Itano C., Levels of evidence: universal newborn hearing screening (UNHS) and early hearing detection and intervention systems (EHDI), Journal of Communication Disorders, 2004, 37(5), p. 451-465, http:/ / dx.doi.org/10.1016/j.jcomdis.2004.04.008

Yoshinaga-Itano C., Achieving optimal outcomes from EHDI, The ASHA Leader, 2011, September 20,16(11), p. 14-17. Retrieved from www.asha.org.

Yoshinaga-Itano C., Sedey A.L., Coulter D.K. et al., Language of early-and later-identified children with hearing loss, Pediatrics, 1998, 102. 